\title{
La mordida del cocodrilo americano (Crocodylus acutus), ¿es potencialmente séptica?
}

\section{Carta al Editor}

Fabio Germán Cupul-Magaña ${ }^{1}$, Armando Rubio-Delgado ${ }^{2}$, Abraham Reyes-Juárez¹ .

${ }^{1}$ Departamento de Ciencias, Centro Universitario de la Costa, Universidad de Guadalajara. ${ }^{2}$ Departamento de Ecología, Subdirección de Medio Ambiente y Ecología, H. Ayuntamiento de Puerto Vallarta. Puerto Vallarta, Jalisco, México.

Morder y asir son los principales mecanismos utilizados por los reptiles para capturar a sus presas. Son tan simples, que sólo requieren que el animal coloque su cabeza cerca del alimento. La aproximación puede realizarse con un rápido movimiento de la cabeza y del cuello, o al desplazar todo el cuerpo. Algunas especies complementan estos métodos con colmillos y glándulas de veneno, como los helodermátidos (escorpión y monstruo de Gila), los eláfidos (coralillo, serpiente marina, etc.) y los vipéridos (cascabel, zolcuate, etc.); o con dientes agudos, como en los crocodílidos (1).

Una especie en particular, el dragón de Komodo (Varanus komodoensis), refuerza su dispositivo de caza con el empleo de un arma letal: una mordida séptica. Esto lo logra gracias a que los residuos de alimento cárnico que se depositan en sus aserrados dientes, son un medio de cultivo para un gran número de bacterias. Se han logrado encontrar cerca de 50 cepas bacterianas diferentes en la saliva de este reptil varánido, de las cuales, al menos cinco, son altamente sépticas. Una presa que haya recibido una mordida, probablemente muera en el lapso de una semana como resultado de una infección generalizada, provocada por la saliva que penetró por la herida (2). De hecho, se ha encontrado que Escherichia coli es abundante en la saliva de ejemplares silvestres $\mathrm{y}$, dos especies de Staphylococcus, predominan en la saliva de ejemplares en cautiverio (3).

Al igual que en el dragón de Komodo, también en algunos representantes del orden de los crocodílidos se ha identificado la presencia de flora bacteriana en la cavidad oral. Sin embargo, estos estudios son escasos y sólo remitidos a dos especies: el caimán americano (Alligator mississippiensis) y el caimán o yacaré overo (Caiman latirostris). En ellos se han aislado bacterias de los géneros Aeromonas, Bacteroides, Citrobacter, Clostridium, Enterobacter, Escherichia, Klebsiella, Pasteurela, Proteus, Pseudomonas, Staphylococcus, entre otras (4).

La diversidad de bacterias arriba citada, es muy similar a la que se encuentra dentro del medio acuático en donde los cocodrilos viven, ya que éstas pueden

Solicitud de sobretiros: Fabio G. Cupul-Magaña, Departamento de Ciencias, Centro Universitario de la Costa, Universidad de Guadalajara. Av. Universidad de Guadalajara No. 203, Delegación Ixtapa, C.P. 48280, Puerto Vallarta, Jalisco, México.

E-mail: fabio_cupul@yahoo.com.mx. Tel. (322) 2262218. Fax. (322) 2811680.

Recibido el 17/Noviembre/2004. Aceptado para publicación el 17/Enero/2005.

Este artículo está disponible en http://www.uady.mx/sitios/biomedic/revbiomed/pdf/rb051617.pdf 


\section{FG Cupul-Magaña, A Rubio-Delgado, A Reyes-Juárez.}

provenir del propio material fecal depositado por ellos dentro de sus estanques de crianza en cautiverio (4, 5) o de la gran cantidad de materia orgánica presente en los ambientes acuáticos costeros en donde habitan (6).

Sin embargo, aunque se encuentra plenamente documentado que los cocodrilos liquidan a su presa al asestarle una mordida que la mate en el acto, o que les permita sujetarla y arrastrarla bajo el agua hasta ahogarla (7) -y no con una mordida séptica como el dragón de Cómodo-, es importante identificar la flora bacteriana presente en su cavidad oral, porque puede ser de utilidad como medida preventiva de salud pública en el tratamiento de heridas provocadas por una mordedura (4), potencialmente séptica para el hombre.

Para conocer las bacterias presentes en la cavidad oral del cocodrilo americano (Crocodylus acutus), se procedió a realizar una serie de cultivos de bacterias en medios nutritivos de agar. Las bacterias fueron colectadas con hisopos estériles de entre los dientes, paladar y región gular de la cavidad oral de tres machos adultos (tallas de 3.40, 3.28 y $2.56 \mathrm{~m}$ ) y de cinco ejemplares juveniles (talla promedio de $0.46 \mathrm{~m}$ ). Es importante mencionar que este es uno de los primeros trabajos que reporta la presencia de flora bacteriana oral en cocodrilos americanos en el medio silvestre.

Los ejemplares juveniles de los cuales se tomaron muestras, fueron capturados en la laguna costera de agua dulce llamada Boca Negra $\left(20^{\circ} 39^{\prime}-20^{\circ} 42^{\prime} \mathrm{N}\right.$ y $\left.105^{\circ} 15^{\prime}-105^{\circ} 17^{\prime} \mathrm{W}\right)$, localizada al norte de la macha urbana de Puerto Vallarta, Jalisco, México. Con relación a los machos adultos, dos de ellos fueron capturados en los canales de drenaje pluvial del Aeropuerto Internacional de Puerto Vallarta y, el otro, en una pequeña poza de agua dulce, a escasos $100 \mathrm{~m}$ del estero Boca Negra. Todas las muestras se colectaron en octubre del 2004, último mes de la temporada de lluvias en la región (junio-octubre).

Dentro de los cultivos fue posible determinar la presencia en abundancia de 10 colonias diferentes de bacterias: Aeromonas hydrophila, Arizona sp, Citrobacter diversus, C. freundii, Enterococcus sp,
Escherichia coli, Klebsiella pneumoniae, Neisseria sp, Pseudomonas sp y Streptococcus viridans. De éstas, sólo Enterococcus sp y S. viridans son grampositivas, el resto son gramnegativas.

En general, se presentaron entre una y cinco colonias bacterianas por ejemplar. La colonia con mayor frecuencia de ocurrencia fue Arizona sp, ya que se aisló en dos ejemplares adultos y tres juveniles. K. pneumoniae, Pseudomonas sp, Neisseria sp y $S$. viridans fueron las que tuvieron un sólo registro, aislándose las dos primeras en juveniles y las dos últimas en adultos (cuadro 1).

Aunque los géneros Aeromonas, Citrobacter, Escherichia, Klebsiella y Streptococcus ya habían sido identificados en la cavidad oral de otros miembros del orden Crocodylia (4), este trabajo documenta por vez primera la ocurrencia de los géneros Arizona, Enterococcus y Neisseria dentro este orden de

Cuadro 1

Frecuencia de ocurrencia de colonias bacterianas en la cavidad oral de ejemplares adultos y juveniles del cocodrilo de río.

\begin{tabular}{|c|c|c|c|c|c|c|c|c|c|}
\hline \multirow[b]{2}{*}{ Bacterias } & \multicolumn{3}{|c|}{ Adultos } & \multirow[b]{2}{*}{1} & \multicolumn{4}{|c|}{ Juveniles } & \\
\hline & 1 & 2 & 3 & & 2 & 3 & 4 & & \\
\hline $\begin{array}{l}\text { Aeromonas } \\
\text { hydrophila }\end{array}$ & & & & & & & & $\mathbf{x}$ & \\
\hline Arizona $s p$ & & $\mathbf{x}$ & $\mathbf{x}$ & $\mathbf{x}$ & $\mathbf{x}$ & & $\mathbf{x}$ & & \\
\hline $\begin{array}{l}\text { Citrobacter } \\
\text { diversus }\end{array}$ & & & $\mathbf{x}$ & & & & & & $\mathbf{x}$ \\
\hline C. freundii & & $\mathbf{x}$ & & & & & & & $\mathbf{x}$ \\
\hline Enterococcus & & & & $\mathbf{x}$ & & $\mathbf{x}$ & $\mathbf{x}$ & & \\
\hline Escherichia co & & & $\mathbf{x}$ & $\mathbf{x}$ & $\mathbf{x}$ & & & & \\
\hline $\begin{array}{l}\text { Klebsiella } \\
\text { pneumoniae }\end{array}$ & & & & & & $\mathbf{x}$ & & & \\
\hline Neisseria $s p$ & $\mathbf{x}$ & & & & & & & & \\
\hline Pseudomonas & & & & & & & $\mathbf{x}$ & & \\
\hline $\begin{array}{l}\text { Streptococcus } \\
\text { viridans }\end{array}$ & & $\mathbf{x}$ & & & & & & & \\
\hline
\end{tabular}

\section{Revista Biomédica}




\section{Mordida del cocodrilo americano.}

reptiles.

Las colonias bacterianas encontradas en la cavidad oral del cocodrilo americano son particularmente patógenas para el hombre $(8,9)$, por lo que la herida provocada por su mordedura, además de que en ocasiones causa en la victima el desgarre del tejido o la fractura del hueso, potencialmente puede abrir el camino para promover la aparición de un cuadro séptico, hecho que es necesario corroborar con el seguimiento de casos clínicos o realizar bioensayos en animales de laboratorio. Mas lo que si es claro, es que generalmente los cocodrilos muestran cierta resistencia a las infecciones microbianas (10), condición que ha sido probada en el caimán americano, al observar que su suero sanguíneo posee propiedades antibacterianas (11).

Palabras clave: mordida séptica, Crocodylus, bacterias.

\section{REFERENCIAS.}

1.- Zug GR. Herpetology: an introductory biology of amphibians and reptiles. San Diego: Academic Press; 1993. p. 527.

2.- Ciofi C. The Komodo dragon. Sci Am 1999; 280(3):84-91.

3.- Montgomery JM, Gillespie D, Sastrawan P, Fredeking TM, Stewart GL. Aerobic salivary bacteria in wild and captive Komodo dragons. J Wildl Dis 2002; 38:545-51.

4.- Huchzermeyer FW. Crocodiles: biology, husbandry and diseases. London: CABI Publishing; 2003. p. 337.

5.- Bolton M. La explotación del cocodrilo en cautividad. Italia: Guía FAO Conservación 22; 1994. p. 156.

6.- González-Farias F, Hernández-Garza M. Aspectos ecológicos de la materia orgánica en lagunas costeras de México. En: Rosa-Vélez J de la, González-Farias F, editores. Temas de oceanografía biológica en México. Ensenada: Universidad Autónoma de Baja California; 1989. p. 79-105.

7.- Cifuentes JL, Cupul FG ¿Los terribles cocodrilos? México: Fondo de Cultura Económica; 2004. p. 136.

8.- Pelczar MJ, Reid RD, Chan ECS. Microbiología. 4a ed. México: McGraw-Hill; 1982. p. 826.
9.- Morfín-Otero R, Rangel-Frausto S, Rodríguez-Noriega E. Infecciones producidas por bacterias grampositivas. Controversias relacionadas al desarrollo de resistencia. Enf Infec Microbiol 2002; 22:46-50.

10.- Cupul-Magaña FG. Cocodrilo: medicina para el alma y el cuerpo. Rev Biomed 2003; 14:45-8.

11.- Merchant ME, Cherie R, Elsey RM, Prudhomme J. Antibacterial properties of serum from the American alligator (Alligator mississippiensis). Comp Biochem Physiol Part B 2003; 136:505-13. 